
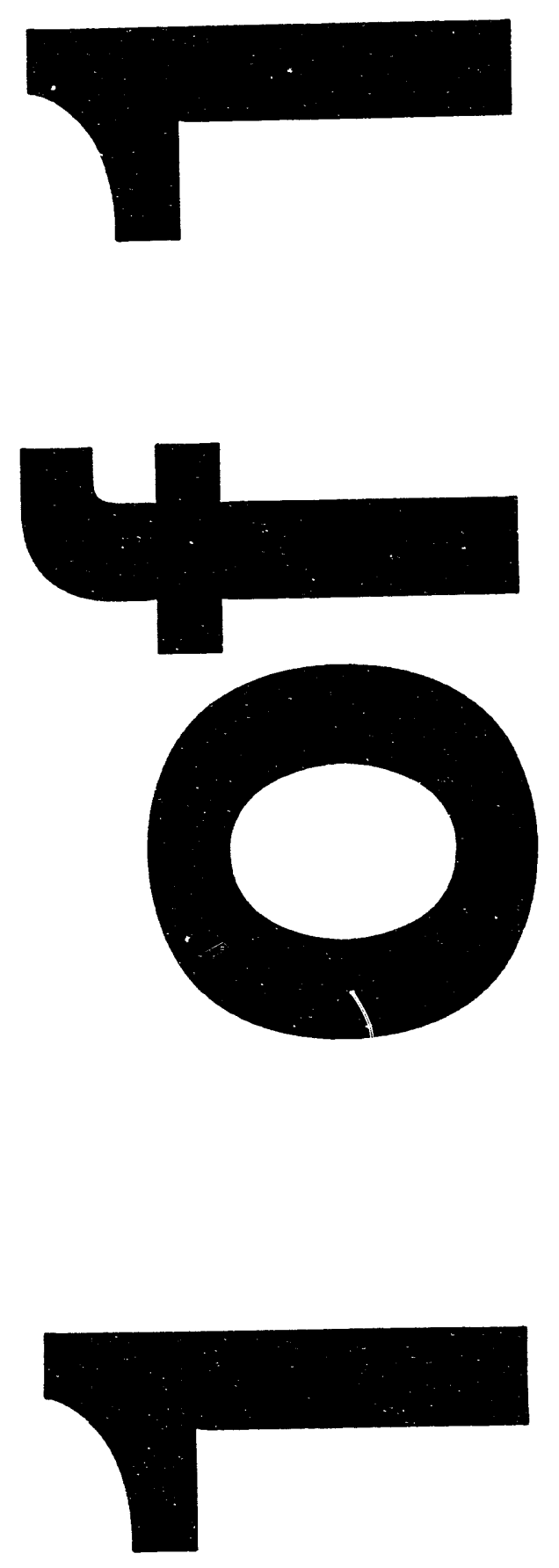
LBL-35320

$\mathrm{UC}-1600$

\section{The Potential for Reducing Urban Air Temperatures and Energy Consumption Through Vegetative Cooling}

May 1994

Dan M. Kurn, Sarah E. Bretz, Benson Huang, and Hashem Akbari Energy \& Environment Division

Lawrence Berkeley Laboratory

University of California

Berkeley, CA 94720

This work was supported by the U. S. Environmental Protection Agency and by the Assistant Secretary for Energy Efficiency and Renewable Energy, Office of Buildings Technologies of the U. S. Department of Energy under contract No. DE-AC03-76SF00098.

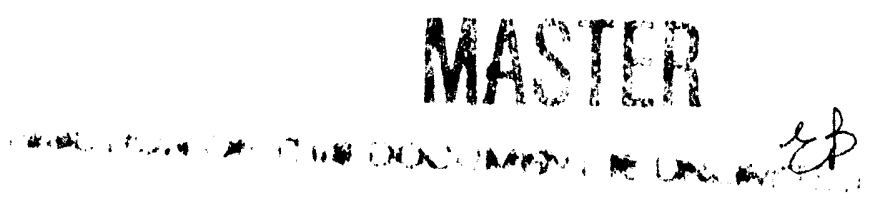




\section{Acknowledgments}

This work was supported by the California Institute for Energy Efficiency (CIEE) through the U. S. Department of Energy, under contract DE-AC0376SF00098. We thank Paul Doose and Melissa Ross of Southern California Edison for their assistance in obtaining the data used in this study.

\section{Disclaimer}

The research reported here was funded in part by the California Institute for Energy Efficiency (CIEE), a research unit of the University of California. Publication of research results does not imply CIEE endorsement of or agreement with these findings, nor that of any CIEE sponsor. 
LBL - 35320

\title{
The Potential for Reducing Urban Air Temperatures and Energy Consumption Through Vegetative Cooling ${ }^{\dagger}$
}

\author{
Dan M. Kurn, Sarah E. Bretz, Benson Huang $\ddagger^{\ddagger}$, Hashem Akbari
}

\author{
Heat Island Project \\ Energy and Environment Division \\ Lawrence Berkeley Laboratory \\ Berkeley, CA 94720
}

\begin{abstract}
A network of 23 weather stations was used to detect existing oases in Southern California. Four stations, separated from one another by 15 - 25 miles (24 - 40 $\mathrm{km})$, were closely examined. Data were strongly affected by the distance of the stations from the Pacific Ocean. This and other city-scale effects made the network inadequate for detection of urban oases. We also conducted traverse measurements of temperature and humidity in the Whittier Narrows Recreation Area in Los Angeies County on Sept. 8-10, 1993. Near-surface air temperatures over vegetated areas were $1-2{ }^{\circ} \mathrm{C}$ lower than background air temperatures. We estimate that vegetation may lower urban temperatures by $1^{\circ} \mathrm{C}$, while the establishment of vegetative canopies may lower local temperatures by an additional $2^{\circ} \mathrm{C}$. An increase in vegetation in residential neighborhoods may reduce peak loads in the Los Angeles area by $0.3 \mathrm{GW}$, and reduce energy consumption by $0.2 \mathrm{BkWh} / \mathrm{year}$, saving \$20 million annually. Large additional savings would result from regional cooling.
\end{abstract}

\footnotetext{
$\dagger$ This work was supported by the California Institute for Energy Efficiency (CIEE) through the U. S. Department of Energy, under contract DE-AC0376SF00098.

‡ Present affiliation: Capital Environmental Eng. Corp., Taipei, Taiwan, R.O.C.
} 


\section{Introduction}

Urban air temperatures can be lowered by reducing the amount of solar energy converted to sensible heat. One method to accomplish this is to increase urban vegetation. Urban vegetation reduces air temperatures both by the direct shading of dark surfaces and by evapotranspiration, the conversion of incident solar radiation to latent heat. These processes can create an "oasis" effect which reduces air temperatures throughout a region.

This paper describes our initial investigation of the potential regional cooling by vegetation in the Los Angeles Basin in Southern California. We analyzed meteorological data gathered at weather stations operated by Southern California Edison Company (SCE) to detect existing "oases" in the Los Angeles Basin. We also performed a set of traverse measurements in Whittier Narrows Recreation Area (WNRA), in Los Angeles County, south of Rosemead. In both efforts, we looked for signs of temperature depression and an increase in specific humidity (mass ratio of water vapor and moist air) which would signal evapotranspiration.

\section{Sources of Moisture in Urban Areas}

Inland humidity is increased by contributions from four moisture sources: precipitation, advection (horizontal transport), anthropogenic (human-made), and natural surface sources. During the summer, precipitation can be neglected as a source of moisture in the Los Angeles Basin; humidity is determined by the three remaining sources.

\subsection{Advection}

Summer weather in Southern California is strongly influenced by the semi-permanent highpressure system in the North Pacific Ocean. Dominant westerly winds induce a strong upwelling of cold subsurface water along the coast. As the warm and moist air of the Pacific passes over this cold water, a bank of marine fog is formed, which is carried over the Basin and which evaporates in the warmer inland air (Elford 1959). This advection of moisture establishes a baseline humidity value, around $10 \mathrm{~g} / \mathrm{kg}$ in the summer, to which other moisture sources make small variations. The advective contribution can be partly quantified by humidity measurements made at the coast, although such measurements fail to quantify the contribution of water droplets (visible as haze) which evaporate inland. 


\subsection{Anthropogenic sources}

Human activity contributes to urban humidity primarily through the combustion of fossil fuels. in the Los Angeles Basin, mobile sources, mainly automobiles, consume about 12 million gallons of fuel oil each day (six million cars at 2 gallons/day), while stationary sources, mainly power plants, consume 72 million gallons of fuel oil and $2.5^{*} 10^{11} \mathrm{ft}^{3}$ of natural gas each year (based on 1985 values from Engineering Division 1986).

During complete combustion, water is produced at a rate of $2800 \mathrm{~g} \mathrm{H}_{2} \mathrm{O}$ per gallon of fuel oil and at $534 \mathrm{~g} \mathrm{H}_{2} \mathrm{O}$ per $\mathrm{ft}^{3}$ of natural gas. Using these conversion factors, we find that anthropogenic sources contribute 394 metric tons of $\mathrm{H}_{2} \mathrm{O}$ daily (see Table 1 ).

Table 1: Consumption of fuel oil and natural gas, and the contribution to atmospheric moisture by mobile and stationary anthropogenic sources in the Los Angeles Basin.

\begin{tabular}{|l|l|l|l|l|}
\hline Source & $\begin{array}{l}\text { Fuel Oil } \\
(\text { million gal.) }\end{array}$ & $\begin{array}{l}\text { Natural Gas } \\
\left(\text { billion } \mathrm{ft}^{3} \text { ) }\right.\end{array}$ & $\begin{array}{l}\text { Water Produced } \\
(\text { metric tons })\end{array}$ & $\begin{array}{l}\text { Specific Humidity }{ }^{\dagger} \\
(\mathrm{g} / \mathrm{kg})\end{array}$ \\
\hline Mobile & 12 & none & 34 & $0.001-0.011$ \\
0.7 & 360 & $0.02-0.11$ \\
\hline Stationary & 0.2 & 0.7 & 394 & $0.02-0.12$ \\
\hline Total & 12.2 & 0.7 &
\end{tabular}

$\dagger$ Assuming the produced moisture is confined over the Basin (with an area of 5,000-10,000 $\mathrm{km}^{2}$ ) and within a mixing-height of $500-2,000 \mathrm{~m}$.

This moisture is mixed convectively throughout the urban boundary layer of air. Taking the area of the Los Angeles Basin as between $5000 \mathrm{~km}^{2}$ and $10,000 \mathrm{~km}^{2}$, and the height of the boundary layer ${ }^{1}$ as ranging from 500 to 2000 meters, the anthropogenic contribution to specific humidity is estimated as $0.02-0.12 \mathrm{~g} / \mathrm{kg}$. This value is much smaller than typical observed humidities (5-10 g/kg), and can be neglected (Ackerman 1987; Jones 1966).

\subsection{Natural sources}

Moisture is produced in large amounts by evaporation from natural sources. The contribution of evapotranspiration, the total evaporation from a plant-soil system, can be determined using estimates of Reference Evapotranspiration, $\mathrm{ET}_{0}$, which is the evapotranspiration

\footnotetext{
${ }^{1}$ The mixing height over a city typically increases during the day from $\sim 500 \mathrm{~m}$ to $\sim 2,000 \mathrm{~m}$ as city air warms and upwelling increases.
} 
rate of a reference crop under specific climatological conditions. The reference crop for the California Irrigation Management Information System (CIMIS) of the California Department of Water Resources is grass which is close clipped, actively growing, completely shading the soil, and well watered. For example, in July, the value of $\mathrm{ET}_{0}$ in Los Angeles is 6.2 inches/month, while in warmer and drier Riverside, it is 7.9 inches/month. The evapotranspiration from a given vegetation type, $\mathrm{ET}_{\mathrm{C}}$, is determined by multiplying $\mathrm{ET}_{0}$ by a crop coefficient, $\mathrm{K}_{\mathrm{C}}$ :

$$
E T_{C}=K_{C} * E_{0}
$$

The use of crop coefficients in urban areas is complicated by the variety of plants, the presence of exotic species, heterogeneous climate conditions, the modification of urban soil, and variations in landscape maintenance. Nevertheless, rough estimates can be made using estimates of urban land cover and average crop coefficients.

Brown and Winer (1986) give the vegetation distribution for the Los Angeles Basin as $13 \%$ turf, $10 \%$ trees and palms, and $4 \%$ shrubs and ground covers. Average crop coefficients for these vegetation types are given in Table 2 (MWDOC). Values of ET 0 for the months of July, August, and September, 1991, were obtained from the California Department of Water Resources for 13 cities in the Los Angeles West and East Basins (portions of Los Angeles, Riverside, and San Bernardino Counties). The evapotranspiration amounts shown in Table 2 were determined by multiplying the average crop coefficients by the average $\mathrm{ET}_{0}$ for the 13 Basin cities.

Table 2: Monthly evapotranspiration (ET) for different land-cover types and for entire urban surface.

\begin{tabular}{|l|l|l|l|l|l|}
\hline Cover Type & Kc & Percentage & ET (inches / month) \\
\cline { 5 - 7 } & & & July & August & Sept. \\
\hline Turf & 0.80 & 13 & 5.8 & 5.6 & 4.4 \\
Trees & 0.50 & 10 & 3.6 & 3.5 & 2.8 \\
Shrubs & 0.40 & 4 & 2.9 & 2.8 & 2.2 \\
Non-Vegetated & 0.00 & 73 & 0 & 0 & 0 \\
\hline Total & 0.17 & 100 & 1.2 & 1.2 & 0.9 \\
\hline \hline Specific Humidity & & & $6-24$ & $6-23$ & $5-19$ \\
(g/kg) & & & & & \\
\hline
\end{tabular}

* Specific humidity if the water evapotranspired over one day were confined in a column of air 500 2000 meters high. Actual contribution to specific humidity depends on mixing height and rate of moisture depletion through advection and condensation. 
The evapotranspiration over the total urban surface is found by averaging the different landcover types weighted by their area. Monthly totals for the summer range from 0.9 to 1.2 inches of water. Again assuming a mixing height of $500-2000 \mathrm{~m}$, we find that the contribution of evapotranspiration to specific humidity ranges between 5 and $24 \mathrm{~g} / \mathrm{kg}$. In reality, condensation into clouds or particulates, mixing with upper air layers, advection, and dewfall continually remove water vapor from the air. While we did not consider these effects, the large estimates clearly demonstrate that advection and evapotranspiration comprise the two dominant sources of urban moisture, and that the presence of vegetative cooling may be effectively determined through measurements of specific humidity.

\section{Effects of vegetation on air temperatures}

Both high-albedo surfaces and increased vegetation help reduce urban air temperatures by replacing the strong heat sources with lesser ones. Thus, they do not mitigate the heat island by cooling the air, but by warming the air less. The effectiveness of a surface in reducing daytime urban air temperatures depends on the amount of heating avoided by using that surface.

By examining the energy balance at each surface, one can compare the effectiveness of a high-albedo and a vegetated surface in mitigating the urban heat island. Consider first a dry, highalbedo surface. Its energy balance is given by the following:

$$
\left(1-a_{d}\right) I=L_{n}+H+G
$$

The left part of this equation describes the net energy entering the surface, where $a_{d}$ is the albedo of the dry surface, and I gives the incident solar radiation. The right half of the equation gives the net energy leaving the surface, where $L_{n}$ is the net long-wave radiation leaving the surface, $H$ is the sensible heat given to the air, and $G$ is the energy conducted into the substrate.

The energy balance of a vegetated surface differs in that energy can also be released through evapotranspiration:

$$
\left(1-a_{v}\right) I=L_{n}+\lambda E+H+G
$$

where $a_{v}$ is the albedo of the vegetated surface, $\lambda$ is the latent heat of vaporization and $E$ the rate of evapotranspiration at the surface. To compare the effectiveness of albedo and vegetation in reducing temperatures, we determine an "albedo" value, $a^{\prime}$, which would prevent the same amount of energy from being absorbed at the vegetated surface as does evapotranspiration:

$$
a^{\prime} I \equiv \lambda E
$$


Then, Equation 3 can be re-written as

$$
\left(1-\left(a_{v}+a^{\prime}\right)\right) I=L_{n}+H+G
$$

The quantity $\left(a_{v}+a^{\prime}\right)$ can be considered the "equivalent albedo" of the vegetated surface which can be compared to the albedo of a dry surface.

For example, let us compare a grove of trees to a paved surface. The albedo of these trees, typically $\sim 0.2$, is slightly higher than that of a paved surface, $0.08-0.15$ (Taha et al. 1992). However, in Los Angeles during the month of July, ignoring the possibility of water stress, these trees transpire $\sim 0.1$ inches ( $3 \mathrm{~mm}$ ) of water daily. The energy released at this evapotranspiration rate, $\lambda \mathrm{E}$, is $80 \mathrm{~W} / \mathrm{m}^{2}$, while the average incident solar radiation on a summer day in Los Angeles is $\sim 400 \mathrm{~W} / \mathrm{m}^{2}$. Thus, the "equivalent albedo" of the vegetated surface is

$$
a_{v}+a^{\prime}=a_{v}+\frac{\lambda E}{I}=0.2+\frac{80 \frac{W}{m^{2}}}{400 \frac{W}{m^{2}}}=0.4
$$

which is the albedo of a light colored surface, even though the trees are visibly dark.

Tall vegetation, such as trees and some bushes, also affects micro-climates by establishing a canopy layer. Wind speeds in the canopy layer are greatly reduced, causing canopy-layer air to be confined longer than in areas without canopies. The effect on air temperature depends on the surfaces within the region of confinement: if canopy layer air is confined to a region containing hot surfaces, canopy-layer air temperatures may be raised; if canopy layer air is confined a region containing cool surfaces, temperatures may be lowered. Thus, for example, researchers exploring residential micro-climates in Sacramento, CA, found only a slight correlation between tree cover and air temperature, since the correlation ignored surface characteristics near the monitoring stations (Sailor et al. 1992). Other measurements, made in the canopy established by an orchard, found larger decreases in air temperatures since the air below the canopy was confined above shaded, wet soil which did not warm the air (Taha et al. 1989).

\section{Analysis of Meteorological Data from SCE Weather Stations}

Meteorological data were obtained from twenty-three weather stations in Southern California operated and maintained by SCE. The data, which covered the period from May 1987 to April 1992, included measurements of ambient drybulb and wetbulb air temperatures, dew point temperature, wind speed and direction, and insolation. We considered hourly data collected in 
1991. We used drybulb and wetbulb temperatures to calculate specific humidity using the methodology described in ASHRAE 1985.

We selected four stations, shown in Figure 1, to examine the climate variations with increasing distance from Pacific Ocean. The stations are separated from each other by $15-25$ miles ( $24-40 \mathrm{~km}$ ), typical of the separation between stations in the SCE network. We excluded cloudy days -- when daily insolation at inland stations was less than $70 \%$ of that expected for a cloudless day ${ }^{2}$--and limited our analysis to July, August, and September, months during which the daytime heat island is most costly. This left 83 days suitable for analysis.

Figure 2 shows the monthly average diurnal profiles of ambient drybulb temperature at the four selected stations for July, August, and September, 1991. The daily maximum temperature increases with distance from the Pacific Ocean. Monthly diurnal profiles of specific humidity at the four stations are shown in Figure 3. During the night, the inland stations are generally drier than the coastal one. In the morning hours, specific humidity at the inland stations rises, sometimes reaching values higher than at the coast. At midday, the specific humidity at the two stations furthest inland (Covina District and San Bernardino District) decreases during all summer months.

These patterns can be understood in terms of the general climatology of the Los Angeles Basin. As discussed earlier, the Basin receives a daily westerly sea breeze which arrives at downtown Los Angeles at 9 AM, at Pomona at 1 PM, and at San Bernardino at 5 PM (Schultz and Warner 1982). This breeze has significant impacts on temperature and humidity profiles.

The climate at Inglewood District station is dominated by the conditions over the Pacific Ocean throughout the day: the air is cool, moist, and undergoes little diumal variation. The moderating influence of the sea breeze diminishes with distance inland, as exhibited by the rise of daily maximum temperatures with increasing distance from the coast. The humidity profiles of Covina District and San Bernardino District stations are typical of inland regions: a sharp rise in the morning from evaporated dew and evapotranspiration, a sharp drop at midday as moist surface air mixes with dry upper air and plants close their stomata in response to high temperatures and water stress (Bidwell 1979; Devlin and Witham 1983; Ting 1982), and a gradual rise as temperatures drop and mixing stops in the late afternoon (Oke 1978). The humidity profile at Montebello District station exhibits a combination of coastal and inland patterns. As at the inland stations, the

\footnotetext{
${ }^{2}$ Horizontal insolation measurements at the San Bernardino District Station (Rialto) showed signs of sensor malfunction between Julian Days 30 and 220. Also, the number of cloudy days at Inglewood District Station was much higher due to coastal clouds.
} 
specific humidity rises in the morning hours, yet the midday humidity depression is either small or missing altogether due to the arrival of the sea breeze.

Additional mesoscale weather patterns arise from the influence of the mountains and surface characteristics, creating a climate characterized by pronounced differences in temperature, humidity, and cloudiness over fairly short distances. Since the SCE weather stations are separated by distances over which mesoscale influences significantly alter the local climate, differences in temperature or humidity cannot be attributed solely to vegetation. Thus, the network cannot be used to isolate the effects of vegetation.

\section{Traverse Measurements at Whittier Narrows Recreation Area}

We performed a series of traverse measurements at Whittier Narrows Recreation Area (WNRA), a large park ( 2 square miles, or $\left.5 \mathrm{~km}^{2}\right)$ in Los Angeles County, centered at the intersection of Highways 60 and 19 (see Figures 1 and 4). It is bordered on the west, south, and east sides by Rio Hondo, Whittier Narrows, and the San Gabriel River, respectively. On the north side, the park is bordered by an urban area with large paved areas (wide streets, sidewalks and parking lots) and few scattered trees and bushes. The northwest corner of the park, were the traverse measurements were performed, is circled by a tree-lined street with adjacent parking lots. The remainder of the park is covered by well watered fields of grass used for sports, with only two thin rows of trees separating the grassy areas.

\subsection{Experimental Procedure}

We performed measurenents along a traverse in the north-west quarter of the park, starting at the northem entrance to the park near Highway 19 and ending near Highway 60 in the western part of the park. Measurements were consistently made at seven sites. Measurement Site 1 was located on city streets beyond the northern border of the park. Sites 2 through 6 were located within the park and surrounded by vegetated areas. Of these, Sites 4 and 6 were shaded by thin rows of trees. The final measurement site, Site 7, was located near a stand of trees and a fence at the shoulder of Freeway 60 . The grass at the shoulder of Freeway 60 was not watered, and thus had turned brown. The distance from Site 1 to Site 7 was approximately one mile $(\sim 1.5 \mathrm{~km})$.

Measurements were made on September 8-10, 1993. These days were characterized by calm, clear conditions and high ambient air temperatures; maximum temperatures at a nearby SCE weather station were $35.8,34.9$, and $34.4^{\circ} \mathrm{C}$ on Sept. 8,9 , and 10 , respectively. Due to the heat, the grassy areas along the traverse were irrigated daily in the early morning hours, ending by 10 AM. This assured that any vegetative cooling would be detected at its maximum intensity, but also 
allowed for the possibility that the temperatures within the park could be depressed by simple evaporative cooling from puddles of water left from the irrigation.

Hand-held units which measured relative humidity and air temperature were used. Identical relative humidity readings were observed when the two units were held together in shielded conditions ${ }^{3}$ but the readings of the two units fluctuated independently by $\sim \pm 5 \%$ RH outdoors, even when the instruments were placed side by side. The indicated accuracy of the temperature readings was $\pm 0.25^{\circ} \mathrm{C}$. The temperature measurements were checked using a dry sling psychrometer before beginning the measurements.

Data were collected at 12 PM, 2 PM, and 4 PM by two members of our team simultaneously, starting at opposite ends of the traverse, and covering the entire path. This yielded two measurements at each site which were averaged to approximate instantaneous measurements. These averages are estimated to be accurate to $\pm 3.5 \% \mathrm{RH}$ and $\pm 0.2^{\circ} \mathrm{C}$.

We examined the humidity in the park in terms of calculated specific humidity, which measures the moisture content in the air independently of temperature variations. We estimate the error in the specific humidity calculations to be approximately $\pm 1.0 \mathrm{~g} / \mathrm{kg}$.

Data from the Montebello District SCE weather station in Rosemead, located approximately 3.5 miles $(5.6 \mathrm{~km})$ from the park, were used to define an urban background condition. However, because these data were not calibrated against the hand-held sensors, and the meteorological differences between the station and the park were not determined, a traverse background condition was determined by averaging measurements made at the extremes of the park traverse.

\subsection{Results}

Figure 5 shows the difference between site and traverse background temperatures for each hour, averaged over the three days of measurement. The air temperatures within the park (Sites 2 through 6 ) were $1-2{ }^{\circ} \mathrm{C}$ below the traverse background temperature. Among these sites, Site 2 is the warmest since it lies outside the ring of trees which surrounds the other measurement sites, and is thus influenced by warm air from the surrounding city and nearby parking lots.

Figure 6 shows temperatures measured at Rosemead compared with traverse background and park interior (average of Sites 2 through 6) temperatures. Data are averaged over the three

\footnotetext{
${ }^{3}$ The two units were found to agree in locations, such as the interior of a car or office, where the air was well mixed and shielded from the wind.
} 
days of monitoring. Interestingly, the Rosemead temperatures are nearly equal to the cooler temperatures within the park. This may due to micro-climate effects or to a miscalibration between the two sources of data.

The differences between site and traverse background specific humidities for each measurement hour and averaged over the days of monitoring are shown in Figure 7. In spite of the observed temperature depression, no clear signal is observed in the specific humidity data. However, as shown in Figure 8, the specific humidity measured within the park is about $6 \mathrm{~g} / \mathrm{kg}$ higher than that measured at the Rosemead weather station.

The lack of an observed rise in specific humidity over the park may be due to the limited accuracy of the measured data (improved from $\pm 1.0 \mathrm{~g} / \mathrm{kg}$ to $\pm 0.6 \mathrm{~g} / \mathrm{kg}$ by averaging three days' measurements). It is also possible that no humidity signal was detected because the sites used for the traverse background measurement were both downwind from portions of the park (see Figure 4), and were thus still influenced by the moist air. However, in such a case, one may also expect the temperature signal to have been suppressed. Another possible explanation involved the fact that Sites 1 and 7 were both surrounded by tall structures (buildings at Site 1, trees and Site 7) which induced strong canopy-layer effects. Over the park, however, since the tree cover was sparse, the air sampled was actually boundary-layer air which may have flowed far above Site 7 , descended into the park, and then risen above the canopy at Site 1. Thus, in essence, the park interior and park background measurements may have sampled different bodies of air.

\section{Estimates of The Potential Neighborhood Cooling By Vegetation}

The results of these traverse measurements at WNRA can be used in conjunction with other results to provide a rough estimate of the cooling attainable in a densely vegetated neighborhood. Since we are interested in reductions in near-surface air temperatures, both boundary layer and canopy layer effects are significant.

Information about the potential boundary-layer cooling is scarce. Traverse measurements within the Recreation Area provide an estimate of this cooling since the park interior sites were located in open grassy fields where no canopy-layer effects were present. However, as discussed above, the observed temperature difference of 1 to $2{ }^{\circ} \mathrm{C}$ may have been exaggerated by the canopylayer effects at the traverse extremes. Further, the Recreation Area represents an impractical method of vegetation cooling, well-irrigated lawns, in the water-scarce environment of Los Angeles. More practical means to cool the Basin with vegetation are the reduction of runoff and the planting of trees which evapotranspire ground water. In all, we can only roughly estimate that the potential air temperature reduction from increasing urban vegetation is near $1^{\circ} \mathrm{C}$. 
We estimate the potential for canopy layer vegetative cooling using several sources. A comparison of temperatures at traverse sites which were in open fields with those under trees (Sites 4 and 6) shows no canopy-layer cooling. although the tree shelter at these sites may have been too thin to establish a dense canopy. Measurements within an orchard near Davis, CA, found a canopy-layer cooling of $\sim 2^{\circ} \mathrm{C}$ throughout the day, and as much as $4-6{ }^{\circ} \mathrm{C}$ in the late afternoon (Taha et al. 1989). Overall, we estimate th' $\lrcorner$ canopy-layer effects can reduce air temperatures by 2 ${ }^{\circ} \mathrm{C}$ on average in areas where dense canopies can be established. Yet, there is evidence that some neighborhoods can be cooled further. Figure 9 shows the difference between air temperatures measured at a heavily vegetated Sacramento neighborhood and those measured at the Sacramento Executive Airport, averaged from August 8 to October 20, 1991. Daytime temperatures in the vegetated area are typically $\sim 3^{\circ} \mathrm{C}$ and sometimes $8{ }^{\circ} \mathrm{C}$ lower than airport temperatures. Nighttime temperatures in the vegetated neighborhood are slightly elevated (around $1{ }^{\circ} \mathrm{C}$ ) because of the wind-shielding and reduction in outgoing long-wave radiation due to the tree cover (Akbari et al. 1992:.).

\subsection{Impacts on Energy Use}

Simple estimates of the impact of vegetative cooling on energy/ use can be made. Previous analysis has shown that the system-wide loads of both SCE and the Los Angeles Department of Water and Power (LADWP) rise by about $3 \%$ with each $1{ }^{\circ} \mathrm{C}$ rise in daily maximum temperature (Akbari et al. 1992b). Thus, we estimate that a hypothetical $1{ }^{\circ} \mathrm{C}$ boundary-layer cooling would reduce peak-loads by $3 \%$. Given a combined peak-load of $20 \mathrm{GW}$ for SCE and LADWP, this amounts to $0.6 \mathrm{GW}$. If such load reductions are achieved for 500 cooling hours each year, cooling-energy savings amount to $0.3 \mathrm{BkWh} / \mathrm{yr}$., worth $\$ 30$ million/year for the utility and customers 4 .

Canopy-layer vegetation effects, felt primarily in residential areas, where vegetative canopies can be established, impact energy use through the reduction in air temperatures, as well as from the shading of building surfaces, and from the reduction in wind speeds, which reduces infiltration. These energy impacts have been measured by several researchers. McPherson et al. (1989) measured $\sim 25 \%$ reduction in air-conditioning by surrounding $1: 4$ scale model homes in Tucson, Arizona, with either turf or shrubs. J. Parker (1983) placed shrubs and trees around a

\footnotetext{
${ }^{4}$ According to recent rate-case put forward by SCE, the utility cost of power is $14.5 \mathrm{c} / \mathrm{kWh}$ on-peak, and $4.0 \mathrm{c} / \mathrm{kWh}$ off-peak. HVAC equipment costs is $2.5 \mathrm{c} / \mathrm{kWh}$. A typical air conditioner may operate for 2000 hours: 600 during peak hours, and 1400 during off-peak hours. Thus, on average, cooling-energy costs $\sim 10 \mathrm{c} / \mathrm{kWh}$ (Rosenfeld et al. 1994).
} 
double-wide mobile home in Miami, Florida, and achieved air-conditioning savings of $24 \%$ over an extended period. A statistical study of homes in Palm Beach, Florida indicated that vegetation at residential sites could save $34 \%$ of cooling energy use (D. Parker 1990). Recently, Akbari et al. (1993) achieved peak reductions of $\sim 0.7 \mathrm{~kW}$ and seasonal-cooling-energy savings of $400 \mathrm{k} W \mathrm{~h}$ by shading two typical homes in Sacramento, CA, with sixteen trees, in agreement with the aforementioned results. Simulations indicate that using half as many trees would reduce these energy savings by half. We estimate that vegetation could be added to only half of the approximately two million homes in the Los Angeles area because of space limitations and preexisting vegetation. Thus, using the results of Akbari et al. and assuming Sacramento and Los Angeles energy savings to be similar ${ }^{5}$, we estimate potential peak reductions of

$$
\left(\frac{0.7}{2}\right) \frac{\mathrm{kW}}{\text { house }} *\left(\frac{2 \text { million }}{2}\right) \text { houses }=0.3 \mathrm{GW}
$$

and cooling-energy reductions of

$$
\left(\frac{400}{2}\right) \frac{\mathrm{kWh} / \text { year }}{\text { house }} *\left(\frac{2 \text { million }}{2}\right) \text { houses }=0.2 \mathrm{BkWh} / \text { year }
$$

worth $\$ 20$ million annually.

Table 3: Potential peak load reductions, annual energy savings, and annual monetary savings from boundary-layer and canopy-layer vegetative cooling in the Los Angeles Basin.

\begin{tabular}{|l|l|l|l|}
\hline & Boundary-Layer & Canopy-Layer & Total \\
\hline Physical effects & $1^{\circ} \mathrm{C}$ cooling & $\begin{array}{l}2{ }^{\circ} \mathrm{C} \text { cooling, reduced } \\
\text { wind speed, shading }\end{array}$ & \\
\hline Peak load reduction & $0.6 \mathrm{GW}$ & $0.3 \mathrm{GW}$ & $0.9 \mathrm{GW}$ \\
\hline Annual energy savings & $0.3 \mathrm{BkWh} /$ year & $0.2 \mathrm{BkWh} /$ year & $0.5 \mathrm{BkWh} /$ year \\
\hline Monetary savings & $\$ 30 \mathrm{million}$ & $\$ 20 \mathrm{million}$ & $\$ 50 \mathrm{million}$ \\
\hline
\end{tabular}

These estimates are summarized in Table 3. It should be stressed that the savings potential through boundary-layer cooling depends on much less substantiated findings than the

\footnotetext{
${ }^{5}$ Measurements in Sacramento confirmed that residential cooling-energy aavings from on-site trees are not temperature dependent. Rather, savings were accrued by reducing wall temperatures and heat gain through windows. In mid-summer, the cooling-energy savings in Los Angeles for houses identical to those monitored in Sacramento would be somewhat smaller due to the higher sun angles. Thus, vegetation would be uptimally sited to shade the roof as well as the walls.
} 
canopy-layer potential. A conservative estimate should neglect the contribution of boundary-layer cooling.

\section{Conclusions}

We have begun to research vegetative cooling in the Los Angeles Basin. An examination of moisture sources concludes that advection and evapotranspiration are the significant contributions to humidity in Los Angeles. Further, a vegetated surface can be as effective as a high albedo surface in reducing the sensible heat transferred to urban air.

Data collected at weather stations operated by SCE in the Los Angeles Basin show large differences in diurnal temperature and humidity profiles according the distance of the station from the Pacific Ocean. As a result, the SCE weather station network probably cannot be used alone to detect evapotranspirative cooling, since the stations are separated by distances over which mesoscale climate differences would obscure the signal from vegetation oases.

Traverse measurements in WNRA on September 8-10, 1993 showed temperatures in the interior of the park to be $1-2{ }^{\circ} \mathrm{C}$ cooler than those at the traverse extremes. No unambiguous specific humidity differences were detected along the traverse, although the specific humidity measured at a nearby SCE weather station was $6 \mathrm{~g} / \mathrm{kg}$ lower than that within the park.

We estimate that vegetation (primarily trees and shrubs) at residential sites can reduce peak loads for SCE and LADWP by $0.3 \mathrm{GW}$, and save $0.2 \mathrm{BkWh} /$ year worth $\$ 20$ million annually. This estimate does not include savings which might occur due to regional, boundary-layer cooling by vegetation. A rough estimate indicates that a hypothetical regional cooling of $1{ }^{\circ} \mathrm{C}$ could result in additional peak load reductions of $0.6 \mathrm{GW}$, and savings of $0.3 \mathrm{BkWh} /$ year worth $\$ 30$ million/year.

Our investigation provides valuable insights for research on urban vegetation oases. The detection of a strong temperature depression through our traverse measurements without an accompanying rise is specific humidity suggests that the effects of vegetation on temperature are far more localized than those on specific humidity. Thus vegetation oases may be best detected through analyzing humidity measurements. However, such a conclusion should first be verified with similar higher resolution humidity measurements.

Supplementing the SCE weather station network with stations operated by the National Weather Service or the South Coast Air Quality Management District may provide sufficient resolution for the detection and analysis of existing urban vegetation oases. However, 
considerable effort would be required to calibrate the various stations so that slight differences in temperacure and larger differences in specific humidity could be assigned to evapotranspiration. Once vegetation oases are located, they can be explored in finer detail with traverse measurements and controlled comparisons of temporary weather stations placed in the area. Future traverse measurements could be improved by performing the measurements more frequently and over a longer time period (for example all day and night) and during different types of days (cloudy, windy, etc.). This effort may be combined with building-energy monitoring and simulation in order to determine the impact of the vegetation oasis on energy use.

\section{Acknowledgments}

This work was supported by the California Institute for Energy Efficiency (CIEE) through the U.S. Department of Energy, under contract DE-AC0376SF00098. We thank Paul Doose and Melissa Ross of SCE for their assistance in obtaining the data used in this study.

\section{References}

Ackerman, B. 1987. "Notes: Climatology Of Chicago Area Urban-Rural Differences In Humidity." Journal of Climate and Applied Meteorology, 26:427-430.

Akbari, H. S. E. Bretz, J. W. Hanford, D. M. Kurn, B. L. Fishman, H. Taha and W. Bos. 1993. "Monitoring Peak Power and Cooling Energy Savings of Shade Trees and White Surfaces in the Sacramento Municipal Utility District (SMUD) Service Area: Data Analysis, Simulations, and Results," LBL-34411, Lawrence Berkeley Laboratory, Berkeley, CA.

Akbari, H., A. Rosenfeld, H. Taha. 1990. "Summer heat islands, urban trees and white surfaces," Proceedings of the American Society of Heating, Refrigeration, and Air Conditioning Engineers, Atlanta, Georgia (February). Also Lawrence Berkeley Laboratory Report LBL-28308.

Akbari, H., S. Bretz, J. Hanford, D. Sailor, H. Taha and W. Bos. 1992a. "Monitoring Peak Power and Cooling Energy Savings of Shade Trees and White Surfaces in the Sacramento Municipal Utility District (SMUD) Service Area. Draft Final Report prepared for the California Institute for Energy Efficiency and SMUD" LBL-33342, Lawrence Berkeley Laboratory, Berkeley, CA.

Akbari, H., S. Davis, S. Dorsano, J. Huang, S. Winnett, eds. 1992b. Cooling Our Communities: A guidebook on Tree Planting and Light-Colored Surfacing. LBL-31587, Lawrence Berkeley Laboratory, Berkeley, CA. 
ASHRAE Handbook, 1985 Fundamentals (Inch-Pound Edition). 1985. American Society of Heating, Refrigerating and Air-Conditioning Engineering Inc.

Bidwell, R.G.S. 1979. Plant Physiology Macmillan Publishing Co., New York.

Brown, D. E. and A. M. Winer. 1986. "Estimating Urban Vegetation Cover in Los Angeles." Photogrammetric Engineering and Remote Sensing, 52 (1):117-123.

Delvin, R.M. and F. H. Witham. 1983. Plant Physiology. Wadsworth Publishing Company, Belmont, California.

Elford, C. R. 1959. "Climates of the States: California." in Climatography of the United States, pp. 86-94.

Engineering Division. 1986. "Power Plants Fuel Use and Emissions in the South Coast Air Quality Management District (1979 - 1984)." South Coast Air Quality Management District, El Monte, CA. pp. iI-6, 7.

Jones, D. M. A. 1966. "Variability Of Evapotranspiration In Illinois." Illinois State Water Survey Circular , 89.

McPherson, E. G., J. R. Simpson, and M. Livingston. 1989. "Effects of tree landscapes on residential energy and water use in Tucson, Arizona," Energy and Buildings, 13: 127-138.

MWDOC (no date) Landscape Water Conservation Guidelines for Orange County, Prepared for the California Department of Water Resources by the Municipal Water District of Orange County (MWDOC), Department of Landscape Architecture, California Polytechnical University, Pomona, and EDAW, Inc.

Oke, T. R. 1978. Boundary Layer Climates. Muthuen Co.

Parker, D. 1990. "Monitored residential space cooling electricity consumption in a hot-humid climate," Proceedings of the 1990 ACEEE Summer Study on Energy Efficiency in Buildings. ACEEE, Washington D.C.

Parker, J. H. 1983. "Landscaping to reduce the energy used in cooling buildings," Journal of Forestry (February): 82-84. 
Rosenfeld, A. H., H. Akbari, S. Bretz, B. L. Fishman, D. M. Kurn, D. Sailor, H. Taha. 1994 "Mitigation Of Urban Heat Islands: Materials, Utility Programs, Updates." To be published in Journal of Energy Efficiency, 1(1).

Sailor, D. J. 1993. "Role of Surface Characteristics in Urban Meteorology and Air Quality." Ph.D. Thesis. LBL-34459, Lawrence Berkeley Laboratory, Berkeley, CA.

Sailor, D., H. Akbari and L. Rainer. 1992. "Measured Impact Of Neighborhood Tree Cover On Micro-climate." Proceedings of the ACEEE 1992 Summer Study on Energy Efficiency in Buildings, (9):149, Asilomar, CA.

Schultz, P. and T. T. Warner. 1982. "Characteristics Of Summertime Circulations And Pollutant Ventilation In The Los Angeles Basin." Journal of Applied Meteorology, 21:672-682.

Taha, H., D. Sailor and H. Akbari. 1992. "High-Albedo Materials for Reducing Building Cooling Energy Use." LBL-31721, Lawrence Berkeley Laboratory , Berkeley, CA.

Taha, H., H. Akbari and A. Rosenfeld. 1989. "Heat Island and Oasis Effects of Vegetative Canopies: Micro-meteorological Field Measurements." Theoretical and Applied Climatology, 44(2):123-138.

Ting, 1. P. 1982. Plant Physiology. Addison-Wesley Publishing Company. 


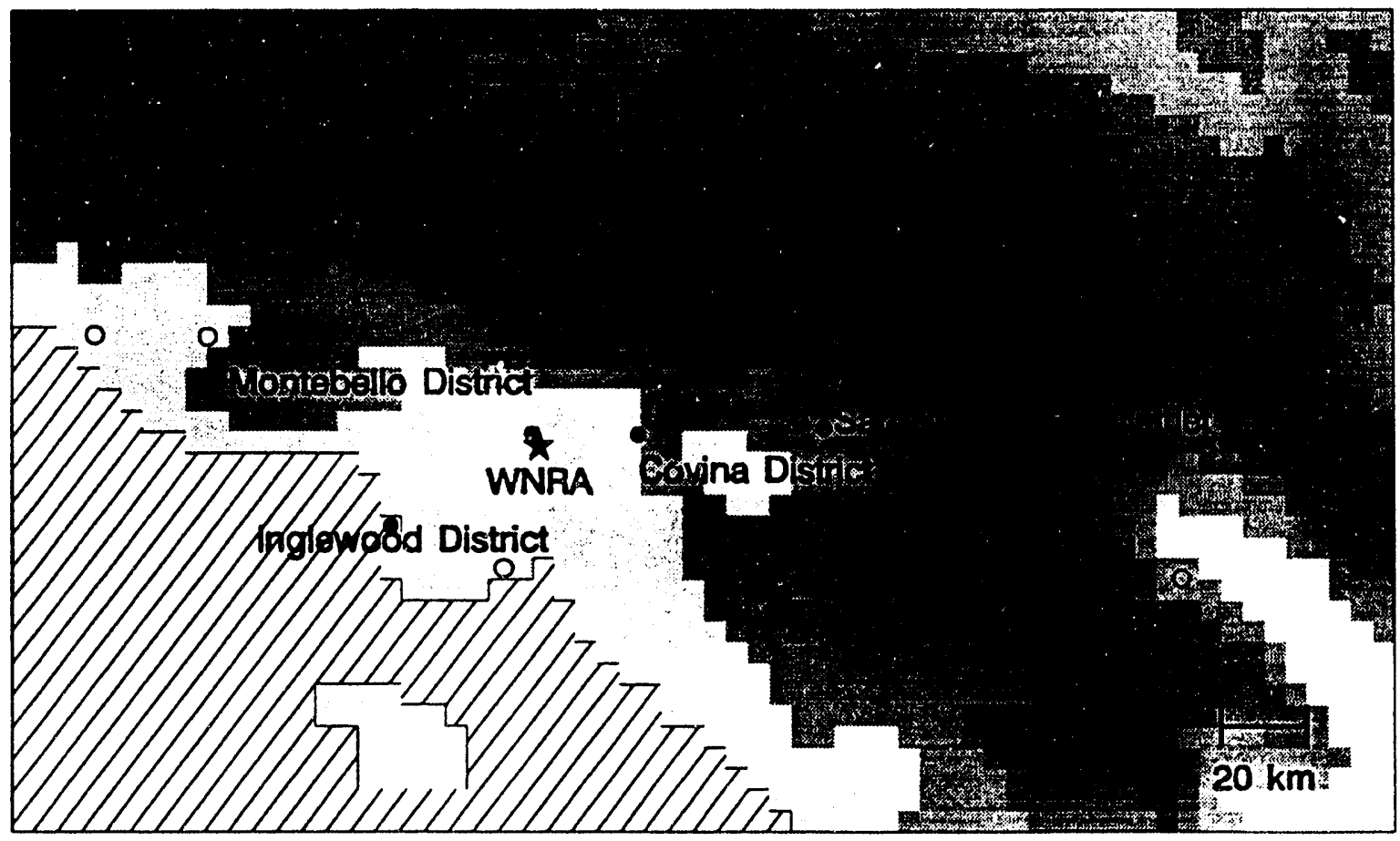

Figure 1: Elevation map of Los Angeles Basin with shading levels every 500 meters. Pacific Ocean shaded in diagonal stripes. Dots show SCE stations used in analysis. Open circles show other SCE stations. Star shows the WNRA. 
a) July 1991

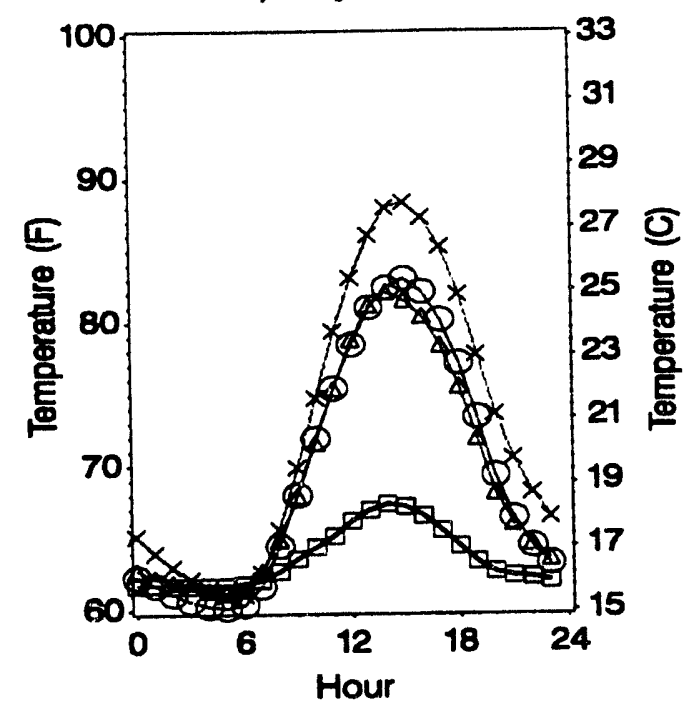

c) September 1991

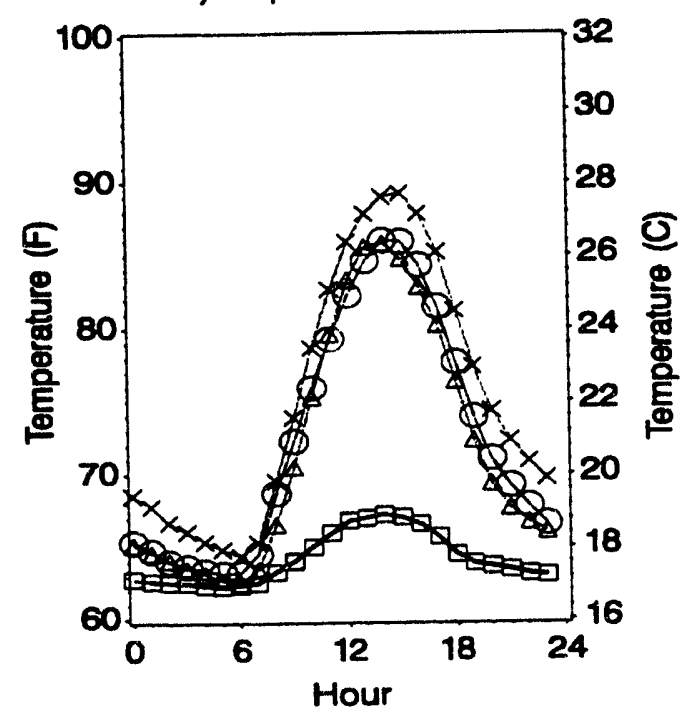

b) August 1991

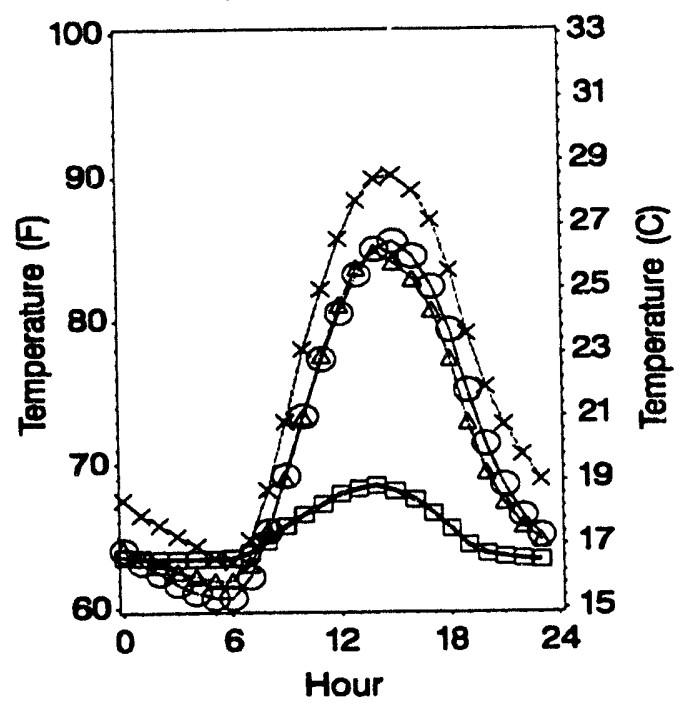

Key to Figures 2 and 3

$\square$ Inglewood District

$\triangle \quad$ Montebello District

$\odot-0$ Covina District

$\star x$ San Bernardino District

Figure 2: Monthly average diurnal variations of ambient drybulb temperature at four SCE weather stations for (a) July, (b) August, and (c) September, 1991. 
a) July 1991

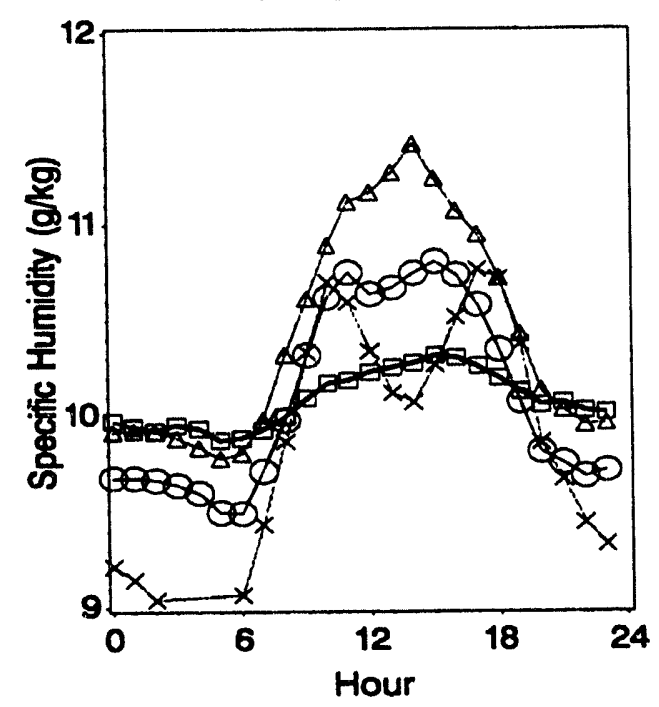

c) September 1991

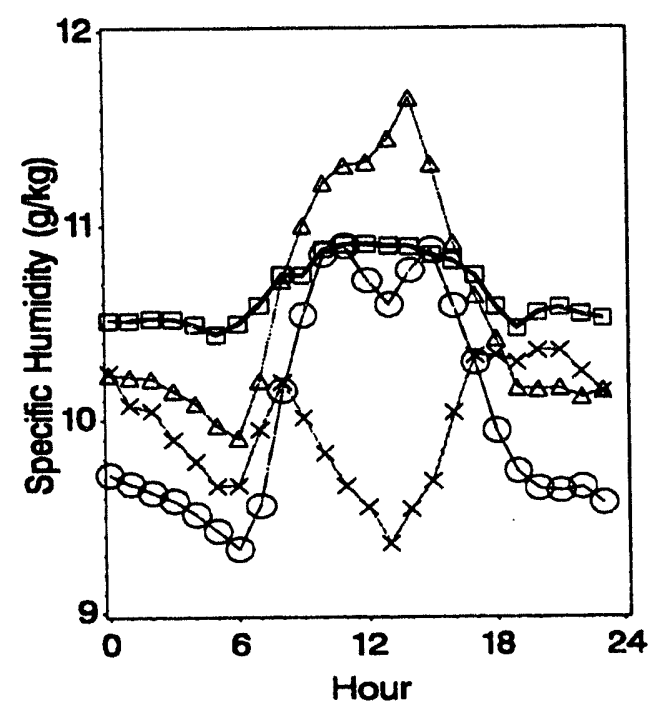

b) August 1991

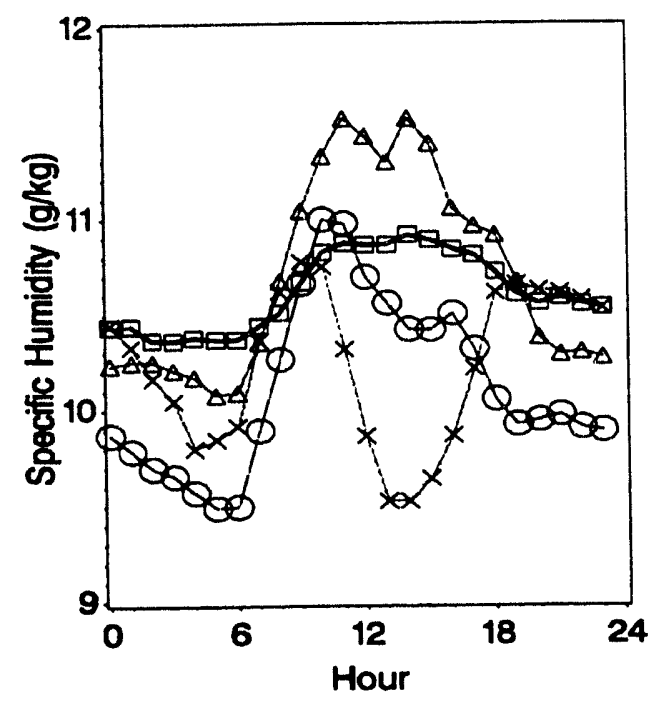

Key to Figures 2 and 3

$\square$ Inglewood District

$\Delta-\triangle \quad$ Montebello District

○) Covina District

$\rtimes \quad$ San Bernardino District

Figure 3: Monthly average diurnal variations of specific humidity at four SCE weather stations for (a) July, (b) August, and (c) September, 1991. 
(1)

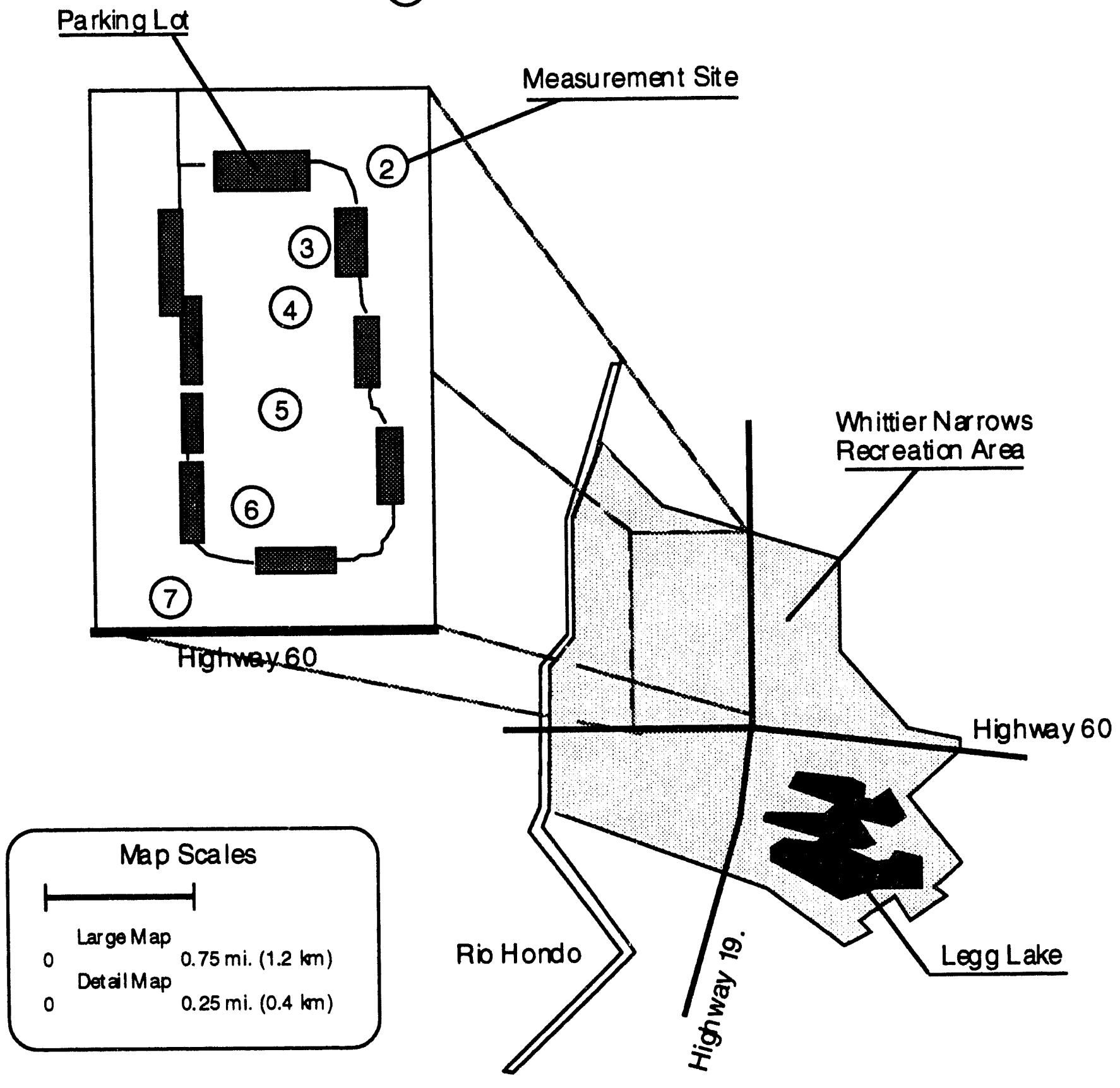

Figure 4: Map of WNRA with detailed map showing traverse path and measurement sites. 


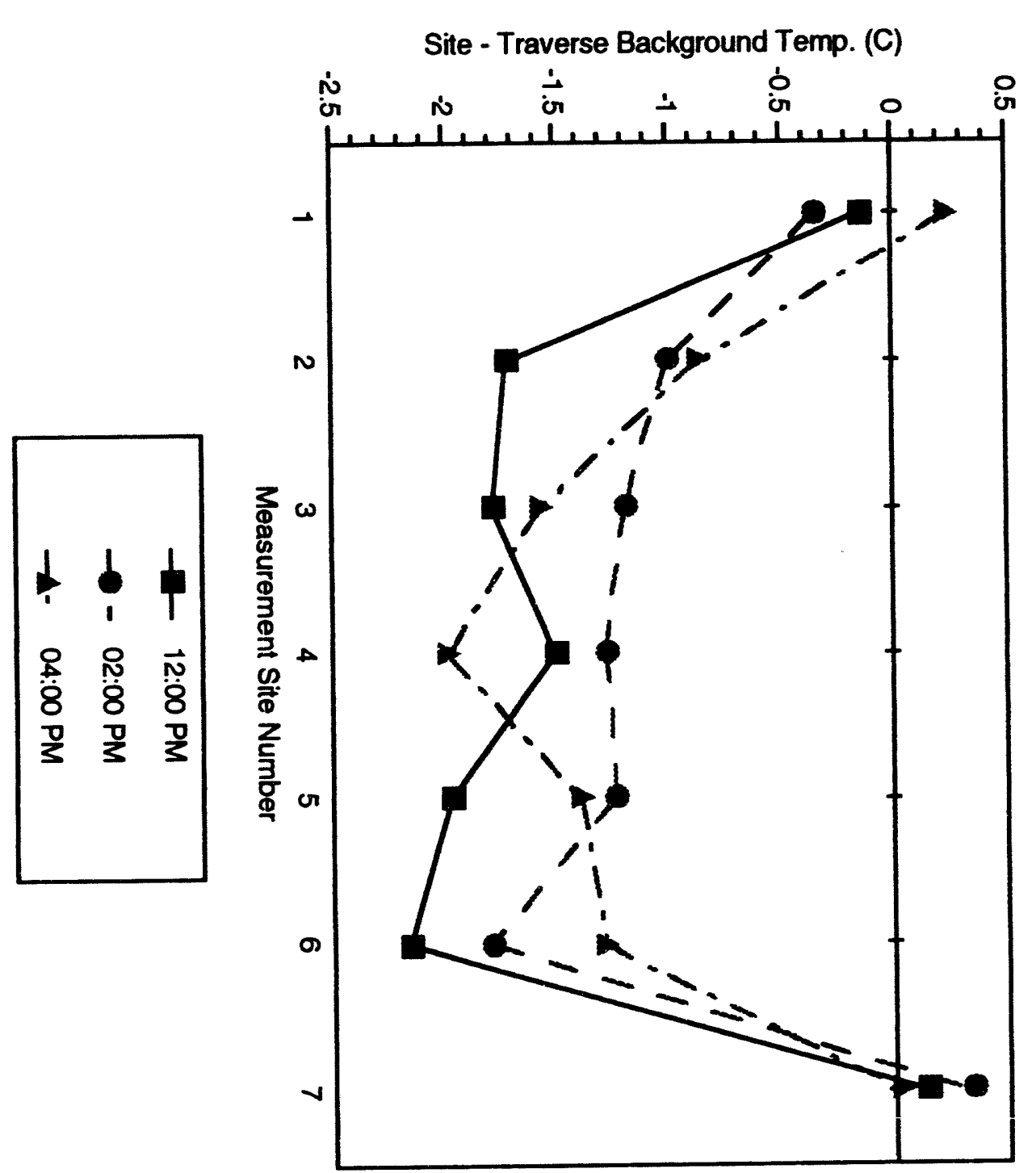



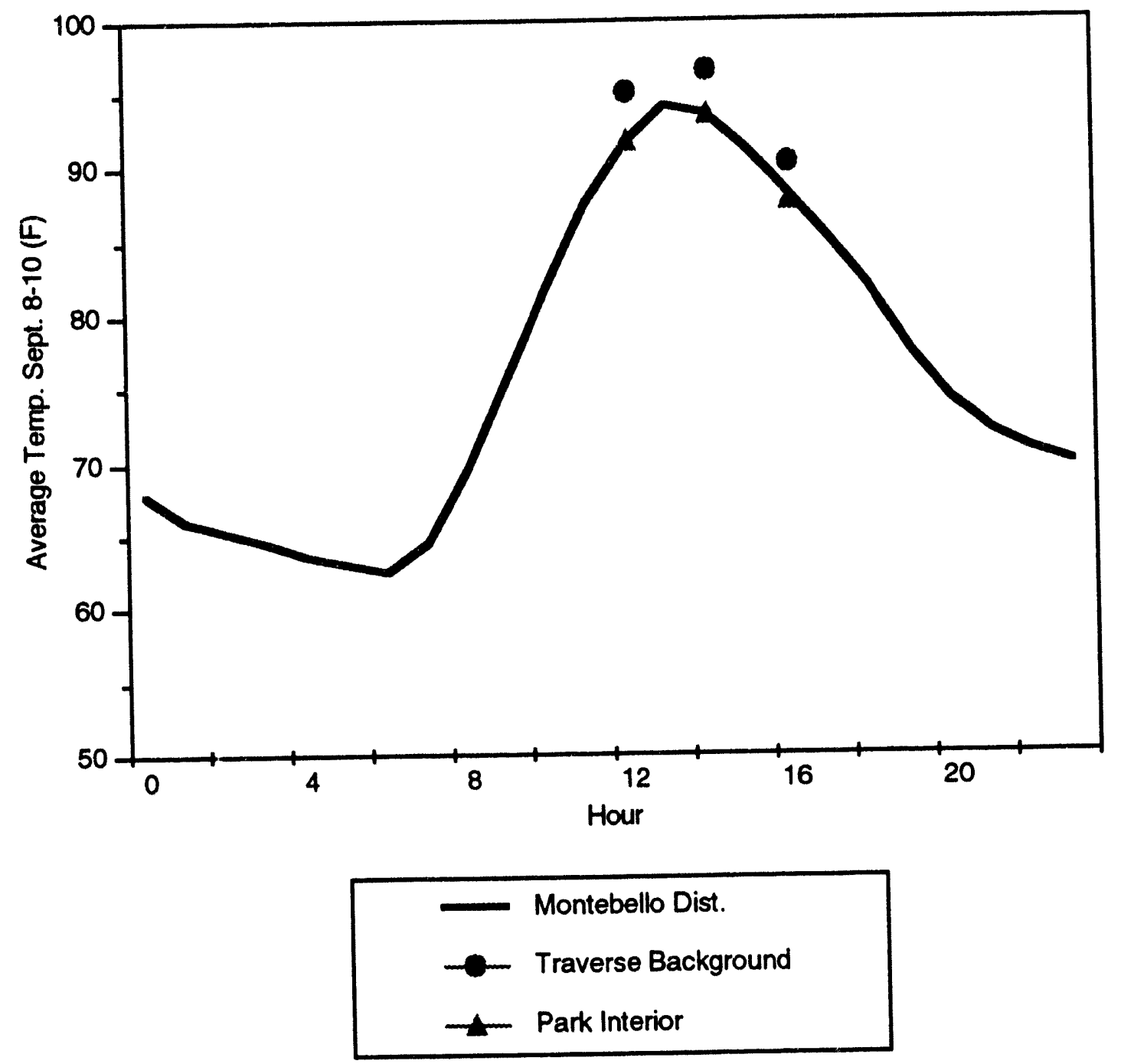

Figure 6: Montebello District Station, traverse background, and park interior temperatures. 

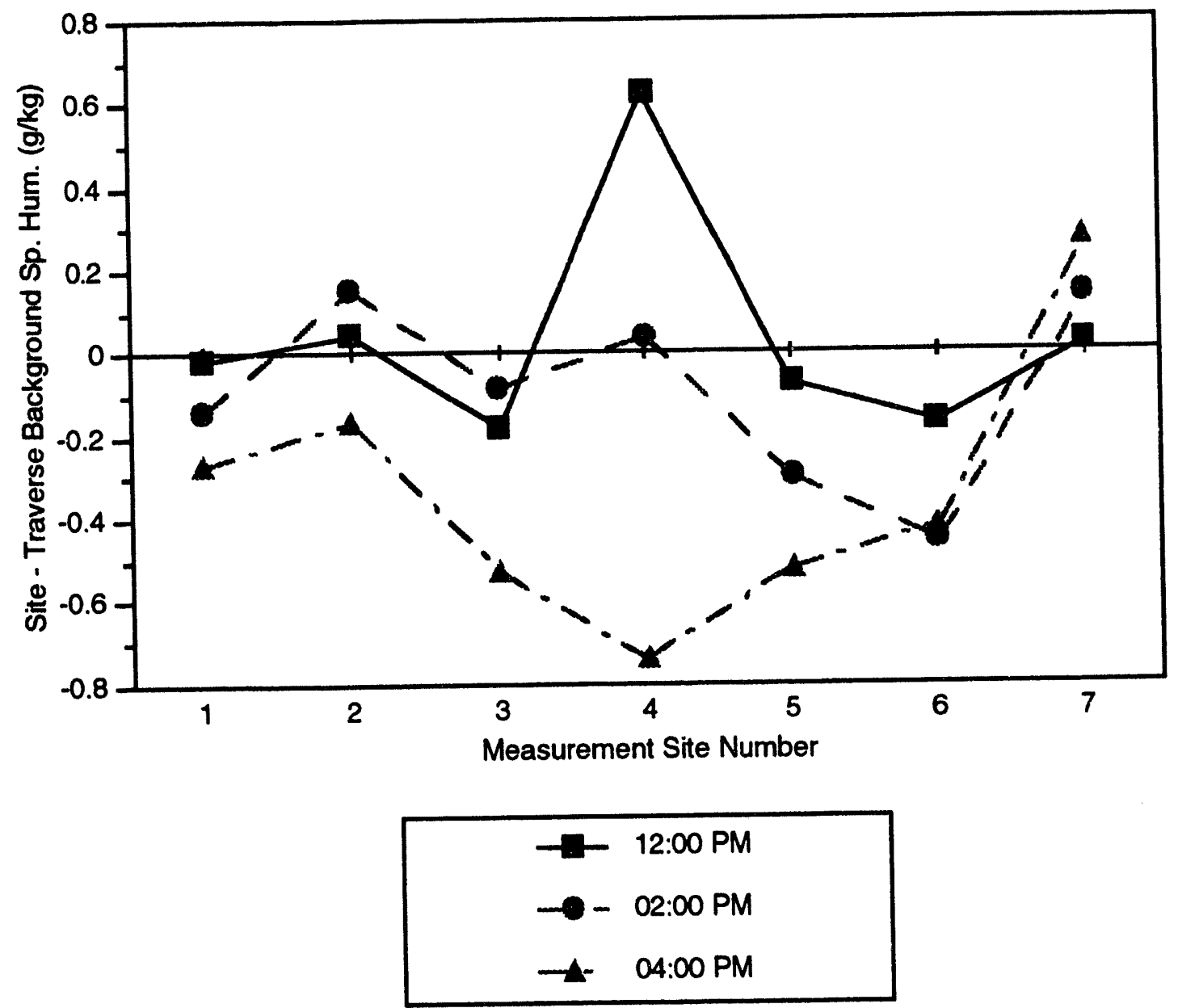

Figure 7: Difference between site and traverse background specific humidity. 

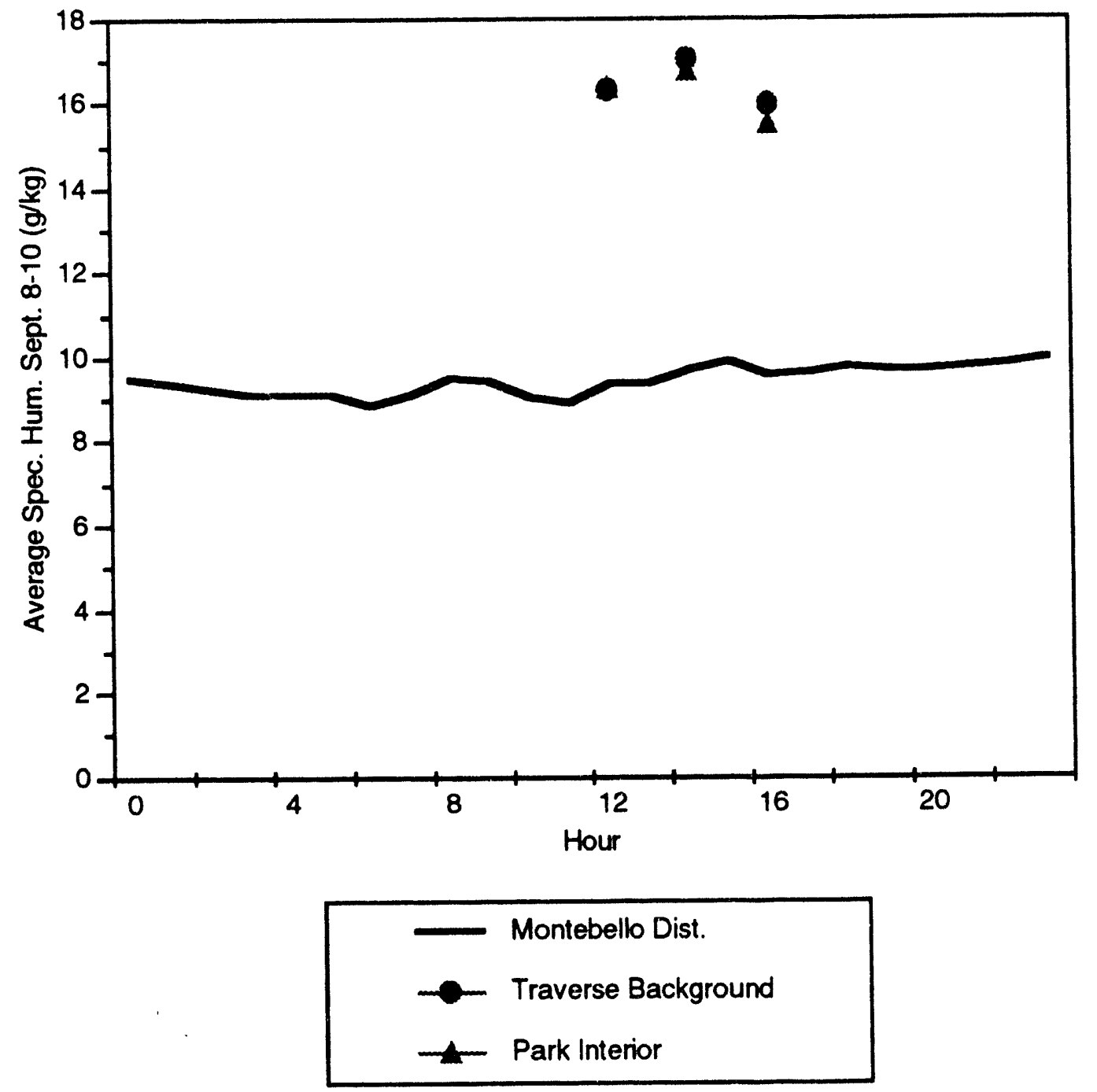

Figure 8: Montebello District Station, traverse background, and park interior specific humidities. 


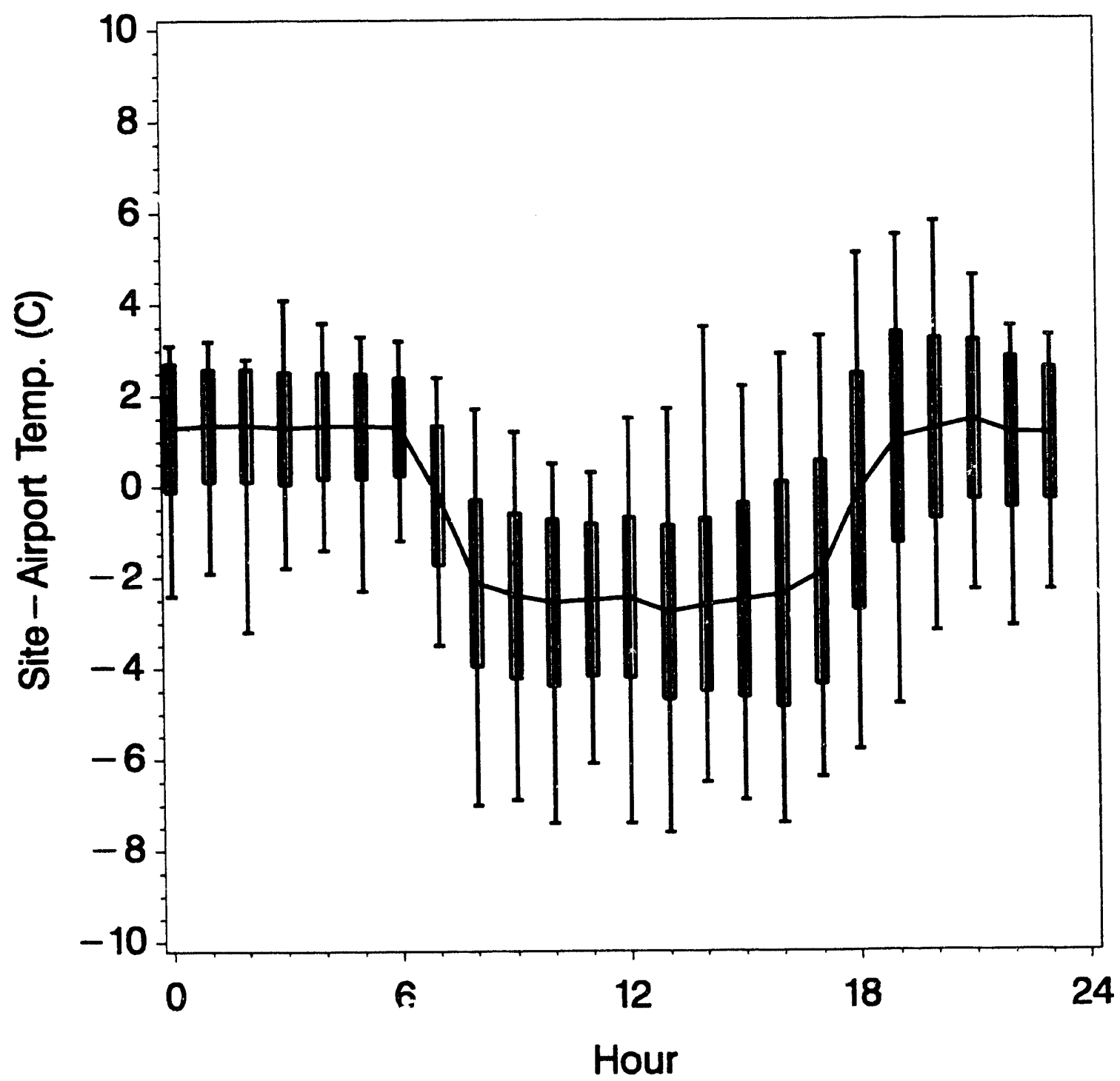

Figure 9: Difierence between residential site and airport hourly temperatures in Sacramento, CA (from Akbari et al. 1992a). 

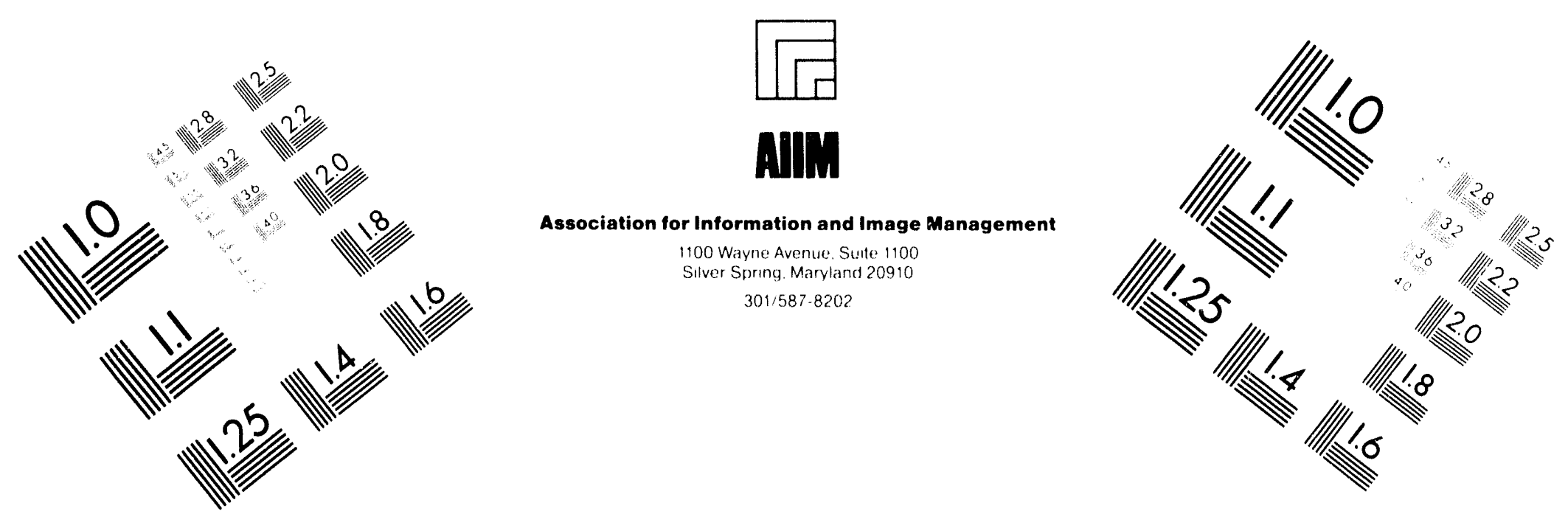

Centimeter

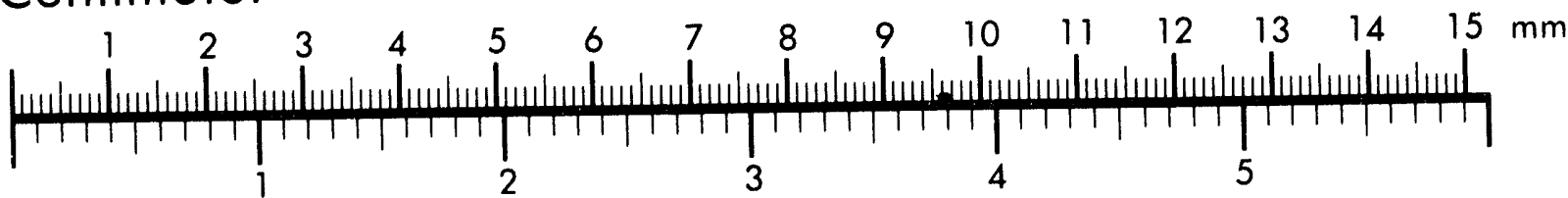
Inches
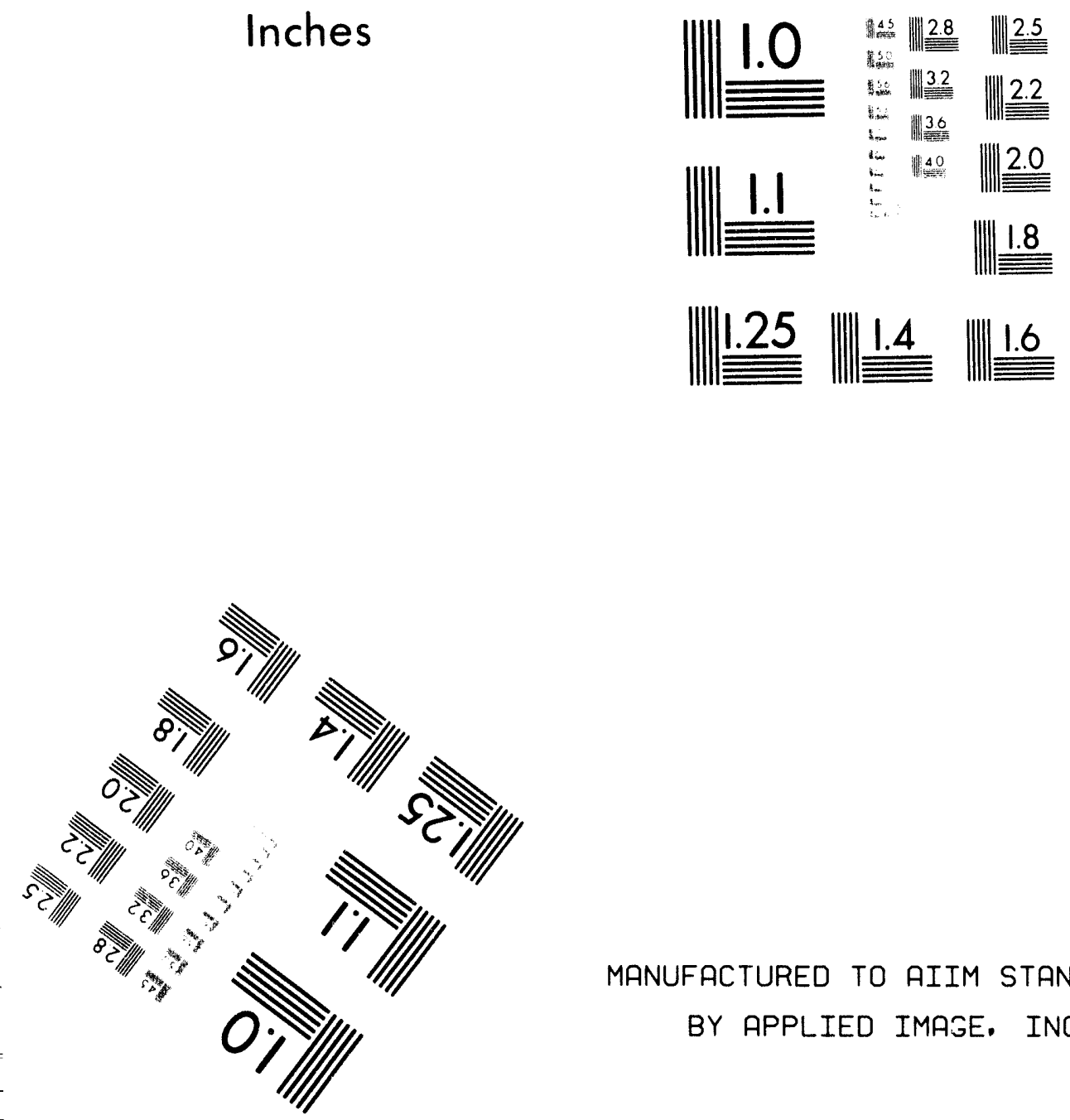

MANUFACTURED TO AIIM STANDARDS

BY APPLIED IMAGE. INC.

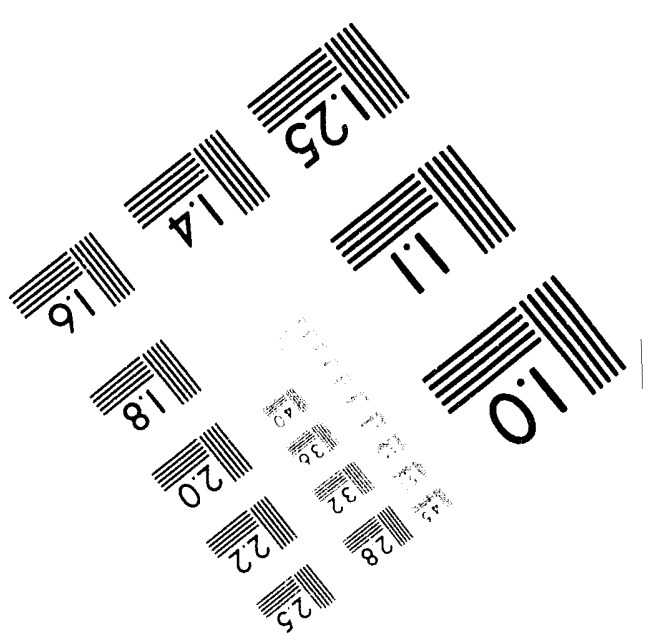



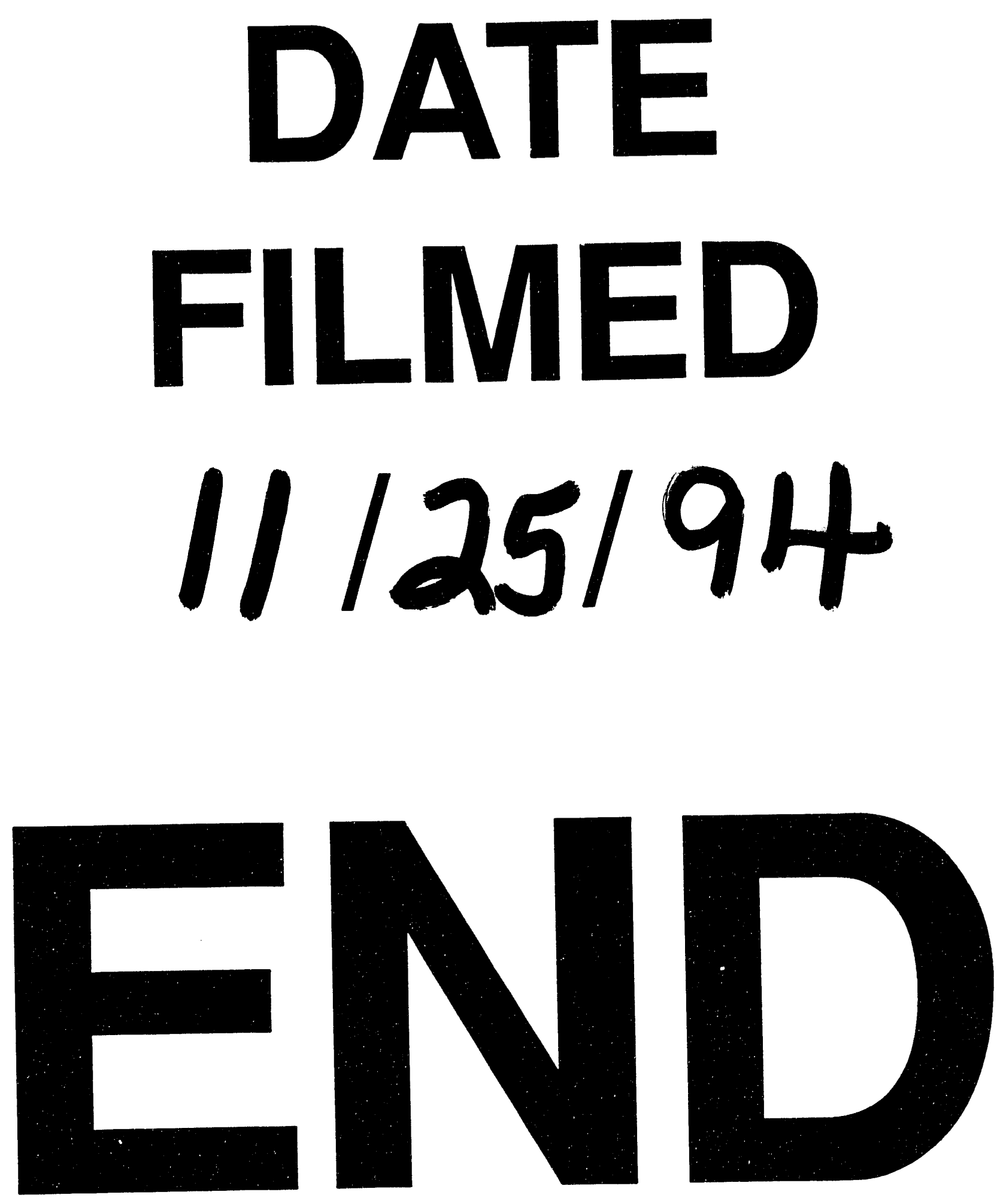